\title{
Looking for the start of metabolic disease in the gut
}

\author{
Max Nieuwdorp is an internist, endocrinologist and vascular medicine specialist at Amsterdam University Medical \\ Centers. He chairs the Diabetes Center there and is chief of the Department and Laboratory of Vascular Medicine.
}

Max Nieuwdorp

\begin{abstract}
n 2002, I took the Hippocratic Oath as a doctor at Utrecht University, the Netherlands. Coming from a family of physicians who were only involved in clinical care for decades, it was a strange move to go into translational science before starting my residency in internal medicine. My first turning point was when I went to another academic medical center (AMC at University of Amsterdam) to have an interview for a position in a doctoral research program. I already had a residency spot at my alma mater. But the enthusiasm of three AMC researchers, Marcel Levi, Joost Hoekstra and John Kastelein (who later became my mentors), influenced me to postpone my residency and first complete a fouryear MD-PhD fellowship in Amsterdam. Working on vascular biology in diabetes, I learned during those years how to perform flow cytometry and an ELISA, techniques I had never read or heard about before. But most of all, I learned that observations in the clinic can be very valuable for defining one's research questions.
\end{abstract}

Eventually, in 2007, I started my internal medicine residency. But my interest in research did not wane. I managed to get funding to do a postdoctoral fellowship at the University of California San Diego (UCSD) under Jeff Esko, working on glycobiology and diabetes in transgenic animal models. The opportunity to move to the US with my young family provided excellent opportunities for family time. When I was not working in the lab, my family spent our time at our beach house and built bonds that proved useful during future challenges. In regard to my scientific career, UCSD had at that time a MD-PhD group (lead by Ajit Varki) where young scientists were able to present their data to and discuss science with established investigators over a beer. On those occasions, I met scientists like Craig Venter, who pointed out the potential importance of the gut microbiota for human disease. Serendipity or not, the next day I changed my daughter's diaper, and I pondered whether fecal microbiota transplantation (now called FMT) would affect human metabolism. After resuming my residency in Amsterdam, I obtained a research grant

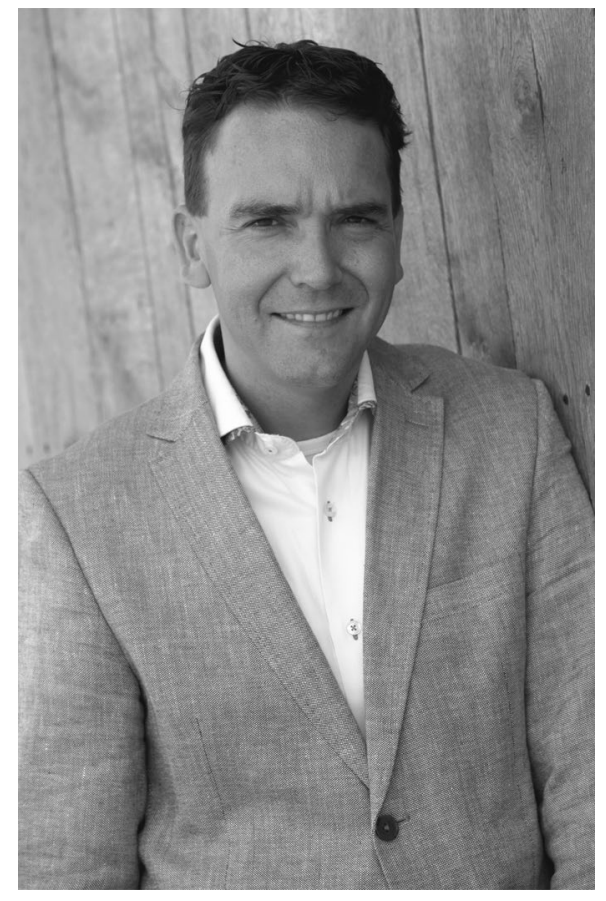

Credit: Max Nieuwdorp

and carried out the first human FMT trials in metabolic syndrome subjects. That first FMT paper in 2012 (coauthored with my microbiology mentor Willem de Vos and Erik Stroes) got so much attention that, while finishing my residency, I had to lecture abroad during the weekend and then fly back from the US to Amsterdam on Sunday evening in order to be in the outpatient clinic on Monday morning. However, I've been fortunate that this multitasking allowed me to build my network at a young age and provided the potential for new collaborations that helped me build my lab. Teaming up with friends who are basic scientists, like Fredrik Backhed, turned out to be instrumental in building my lab. Together we showed that that the metabolic effects of the gutmicrobiota in humans are usually less obvious than in mice, but are still clinically significant when tested in humans.

My second turning point was more personal: my son got liver cancer and needed a liver transplant a few years ago. This forced me to step out of the scientific arena for one year and serve as his living related liver donor and go through rehab thereafter. It made me realize that even though working long hours is rewarding, life is short and one cannot do everything alone. I learned that sharing the stage and even giving it away to other team members (especially women, who make up $50 \%$ of my group and bring a different dynamic to the lab) were pivotal. I was raised by a mother who was an active feminist, and I felt very proud when I saw that my values trickled down to other group members who spontaneously offered to take over the experiments of their female colleagues on maternity leave to prevent these women's research projects from slowing down. Finally, I began to prioritize time with my family even more (which usually means that I have to get up early in the morning to do science before clinic begins, or when my kids come back from school and my wife is at work as a midwife). My improved time-management skills also helped me to visit every home game of Amsterdam Soccer Club Ajax with my son and indulge in my wine-making hobby. A few years ago, I bought a small vineyard in Burgundy with four friends, where we produce our own pinot noir wine.

In the 15 years I have been in scientific research, I have watched translational science become more expensive and demand multidisciplinary interactions, including hiring bioinformaticians. Nevertheless, studying the largely unexplored roles that the microbes inside us play in our metabolic pathways has been fascinating. However, I modestly acknowledge that this is only possible because we all are standing on the shoulders of giants. After all, it was the Greek physician Hippocrates who postulated almost 2,500 years ago that all disease starts in the gut.

\section{Max Nieuwdorp}

Department of Internal and Vascular Medicine, Amsterdam University Medical Centers, Amsterdam, the Netherlands.

e-mail:m.nieuwdorp@amsterdamumc.nl

Published online: 8 May 2019

https://doi.org/10.1038/s41591-019-0419-1 